\title{
Facebook e participação política: o que dizem os jovens do \#OcupaAlemão
}

\author{
Ana Paula Silva* \\ Wania Gonzalez**
}

\begin{abstract}
Resumo
O texto propõe uma reflexão sobre o uso do Facebook, como campo de aprendizado e práticas políticas, por uma parcela da juventude do Rio de Janeiro, os participantes do \#OcupaAlemão. Este coletivo de jovens cariocas propõe soluções para as demandas da cidade, a partir de suas vivências na comunidade, onde utilizam a rede da Internet, para dar visibilidade às suas produções, além de trocar informações, organizar e mobilizar (novos) sujeitos para ocupar os espaços públicos. Os dados apresentados são resultantes de uma pesquisa, de caráter qualitativo, realizada nos anos de 2013 e 2014. Mediante dois eixos temáticos: tecnologias da informação e da comunicação (TICs) e espaços não formais de ensino é que se procede à análise dos dados levantados no campo, por meio da observação, tanto no campo virtual como nas atividades presenciais, e das entrevistas semiestruturadas com os sete participantes do \#OcupaAlemão. A interpretação dos dados foi efetuada à luz de autores que discutem as potencialidades da educação não formal na construção de valores relacionados à cidadania: Gadotti (2005), Libâneo (2007), Trilla e Ghanem (2008) e Gohn (2010) e de pesquisadores que abordam a complexidade do aprendizado em ambientes virtuais tais como: Levy (1999), Castro (2012) e Pretto (2008). Os resultados apontam que existem espaços de interação digital que colaboram para a formação de uma nova cultura política dos jovens internautas, porém, essa formação de um cidadão participativo, dependerá da interação de outras redes sociais offline e online que direcione para este fim.

Palavras-Chave: Educação não formal; Facebook; Aprendizagem política.
\end{abstract}

\section{Facebook and political participation: What the youth of \#OcupaAlemão have to say.}

\begin{abstract} to this end.

Keywords: Non-formal education; Facebook; Political learning.

\section{Introdução}

O texto propõe uma reflexão sobre o uso do Facebook, como campo de aprendizado e práticas políticas, por uma parte das juventudes de favelas da cidade do Rio de Janeiro, os participantes do \#OcupaAlemão. Este coletivo de jovens cariocas propõe soluções para as demandas da cidade do Rio de Janeiro, a partir de suas vivências na comunidade, onde utilizam a rede da Internet, para dar visibilidade às suas produções, além de distribuir e trocar *Endereço eletrônico: dasilva.apaula@gmail.com

** Endereço eletrônico: waniagonzalez@gmail.com
\end{abstract}

The text proposes a reflection on the use of Facebook as a learning field and political practices, by part of the youth of Rio de Janeiro, participants of \# OcupaAlemão. This collective of young Rio citizens proposes solutions to the demands of the city, from their experiences in the community, where they use the Internet, to give visibility to their productions, as well as exchange information, organize and mobilize (new) subjects to occupy public spaces. The data presented are the result of a qualitative research, conducted in the years 2013 and 2014. In two themes: information and communication technologies (ICTs) and non-formal educational spaces it is analyzed the data collected in the field, through observation, both in the virtual field and in classroom activities, and semistructured interviews with seven participants \# OcupaAlemão. Data interpretation was done in the light of authors who discuss the potential of non-formal education in building citizenship-related values: Gadotti (2005), Libâneo (2007), Trilla and Ghanem (2008) and Gohn (2010) and researchers addressing the complexity of learning in virtual environments such as Levy (1999), Castro (2012) and Pretto (2008). The results show that there are digital interaction spaces that contribute to the formation of a new political culture of young Internet users, however, this formation of a participatory citizen will depend on the interaction of other offline and online social networks point

informações, organizar e mobilizar (novos) sujeitos para ocupar os espaços públicos. No que tange aos procedimentos metodológicos adotados, utilizamos como técnicas de coletas de dados a observação em algumas atividades presenciais, tais como: "rolé afetivo" que são os passeios nos espaços da favela do Alemão, a fim de integrar a cidade; "GatoMídia" que são encontros de formação e discussão política com diversos temas, além de eventos pontuais como a realização da biblioteca comunitária dos Mineiros, no alto do morro do Alemão. Castro, Ferreira e 
Gonzalez (2013) a respeito da técnica de observação, afirmam que para obter dados não verbais relacionados ao tema estudado, fatos e comportamentos deverão ser vistos cuidadosamente, para que seja possível fazer uma avaliação e comparar com os relatos nas entrevistas e questionários. Pois, assim fica mais compreensível entender o contexto sociocultural de um grupo ou comunidade e até na observação de uma página de Facebook. Optamos, no entanto, por manter o anonimato dos jovens do coletivo \#OcupaAlemão, tratando-os apenas como "integrantes" de um a sete.

As investigações na página de Facebook do coletivo possibilitaram cotejar as práticas da "vida real" com a "vida social online, apesar das distinções entre os espaços presenciais e digitais, há uma interrelação entre online e offline " (FRAGOSO et all, 2011, p.174). Para isso, escolhemos como metodologia a etnografia virtual, que tem como proposta analisar "no/de e através do online" vinculada ao offline, e não separadamente porque são contextos inseparáveis, para assim buscarmos entendimento sobre as práticas comunicacionais e sociais produzidas e geradas na página de Facebook do coletivo \#OcupaAlemão (FRAGOSO et al., 2011). A interpretação dos dados foi efetuada à luz do quadro teórico, principalmente a partir das reflexões de autores que discutem as potencialidades da educação não formal na construção de valores relacionados à cidadania, entre os quais destacamos: Gadotti (2005), Libâneo (2007), Trilla e Ghanem (2008) e Gohn (2010) e de pesquisadores que abordam a complexidade do aprendizado em ambientes virtuais tais como: Levy (1999), Castro (2012) e Pretto (2008).

Logo, propõem-se a discussão desses novos fenômenos de práticas sociais que interagem online e offline, sob a ótica tanto do reconhecimento da existência de diferentes espaços formativos quanto dos teóricos que discutem as Tecnologias da Informação e da Comunicação (TICs), buscando provocar reflexões acerca da Internet e, particularmente, do Facebook como espaços de aprendizagem e prática política para mudanças na sociedade contemporânea.

No novo cenário midiático que é a Internet, o Facebook se apresenta atualmente como meio e espaço para socialização principalmente entre a juventude. Ele vem influenciando novos processos de aprendizagens e saberes, seja indiretamente, quando se lê algo ou se opina, seja diretamente, por meio dos diferentes tipos de aprendizagens que podemos realizar, conforme Gohn (2010) aponta em sua análise acerca das diferentes aprendizagens que ocorrem nos espaços não formais de ensino. Para esta autora, as potencialidades desses espaços formativos residem: a) na aprendizagem prática: espaço para organização e participação efetiva na sociedade; b) na aprendizagem política: discussão de direitos, acompanhamento e reivindicação das responsabilidades do poder estatal governamental com a sociedade; c) na aprendizagem cultural: espaço para reafirmação das identidades, produção estética sobre as origens, arte, cultura, lazer, etc.; d) na aprendizagem cognitiva: apreensão e expressão de temas, problemas e conteúdos, também facilitados pela participação em outros espaços como a escola, a rua, eventos, entre outros tipos de aprendizagens como ocorre na educação não-formal. Entre os diferentes tipos de aprendizado destacados pela autora, este texto privilegia a discussão da aprendizagem política dando destaque ao Facebook.

Portanto, refletir sobre as possíveis potencialidades e desafios desse tipo de aprendizado, instrumentalizado pelo Facebook, consiste na aposta desta pesquisa que almeja contribuir para a desconstrução do senso comum de que a rede social virtual em questão é somente para "isolamento", "entretenimento", e, logo, comumente associada à "perda de tempo". Contudo, o entretenimento também é uma forma de aprendizado e troca de saberes. Ficar por algumas horas diante da tela do computador, considerado entretenimento para alguns, traz também competências para o desenvolvimento, como, por exemplo, Lévy (1999) nos aponta dizendo que estamos em contato com discursos, com múltiplas vozes, universos de significados aos quais também contribuímos com nossa participação, e, que, ao mesmo tempo, têm habitado nossa leitura de mundo.

O desafio é, segundo Pretto (1996; 2008), construir novos espaços físicos, como uma escola, por exemplo, que receba o aluno contemporâneo e seus conhecimentos, pois o modelo antigo de escola que predomina, não comporta jovens que convivem intimamente com as tecnologias e trazem muita criatividade, imaginação e têm raciocínio rápido (PRETTO, 1996).

Talvez seja incompreensível para alguns adultos, que participam em certa medida das redes sociais, adotar este novo espaço como campo do saber e reconhecer a riqueza comunicacional posta nalem rede pelos jovens contemporâneos. Isto, em certa medida, acontece por não terem o hábito de lidar com essas técnicas, muitas vezes complexas, e elas não fazerem parte de seu repertório cultural e 
contexto social, como analisa Couto Junior (2012). Mas esses argumentos de que usar as TICs é tarefa difícil, pois não fazem parte do ambiente natural, precisam urgentemente ser superados (PRETTO, 2008), uma vez que a sociedade tornou-se digital.

Utilizamos o artigo de Castro (2012), publicado na Pesquisa TIC Domicílios e Empresas 2011, para complementar o pensamento de Couto Junior (2012) sobre a riqueza comunicacional contemporânea e para contribuir com os pensamentos de Pretto (1996). Sobre o aluno contemporâneo e os conhecimentos que ele traz, a autora diz: "[...] a revolução digital nos permitiu compreender o que é um cidadão comunicador [papel antes designado a poucos] e nos deu acesso a tantas diferentes culturas, opiniões e informações" (CASTRO, 2012, p. 101, grifo nosso) ${ }^{1}$. E podemos notar isso: uma imensidão de conteúdos produzidos individualmente e/ou coletivamente por diversos jovens [e adultos também]. Uma produção cultural com muita intensidade na sociedade atual por conta da velocidade de compartilhamentos. Assim, as TICs ajudam a transformar esse indivíduo em produtor e não simplesmente em consumidor. A produção da cultura agora se torna digital (PRETTO, 2008).

A fruição do que as tecnologias poderiam proporcionar, em especial a Internet, foi sobremaneira absorvida pelos mais jovens que entenderam rapidamente que ela poderia juntar e articular as redes já existentes, criando a possibilidade de comunicação com todos, sem que houvesse um articulador central para isso (PRETTO, 2008). Destacaremos, mais adiante, o importante papel das ONGs nesta questão. Mas, de certa maneira, os indivíduos dos séculos XX e XXI estão tendo o convívio mais próximo com a leitura e a escrita, como Pretto (2008) analisa ao apontar que na Internet as pessoas têm escrito mais por suas manifestações espontâneas, ajudando assim, a produzir conhecimentos.

Frente ao exposto, avalia-se que o coletivo \#OcupaAlemão reúne características importantes para a investigação proposta, tais como: a) se insere no contexto atual do uso crescente das TICs por jovens oriundos de áreas de vulnerabilidade social; b) seus usuários são ativistas online e offline; c) os seus integrantes têm participado de projetos sociais; e, d) é um coletivo atuante nas favelas pelas suas ações políticas.

Diante da contextualização apresentada, temos a seguinte questão de estudo: os jovens das classes menos favorecidas vêm participando politicamente na sociedade, pelo uso do Facebook, então, como a rede social reflete essas práticas e torna-se campo de aprendizado, sobretudo político para os jovens?

Esta indagação abriu a possibilidade de discussão acerca dos diferentes espaços formativos existentes na sociedade atual mediante a articulação do enfoque das tecnologias da informação e da comunicação como espaços não formais de ensino. É por essa perspectiva que se construiu o referencial teórico em que se fundamenta o presente trabalho. Mediante esses dois eixos temáticos, é que se procede à análise dos dados levantados no campo, por meio da observação e das entrevistas semiestruturadas.

\section{O Complexo do Alemão e o perfil dos sujeitos da pesquisa}

O Alemão é um complexo de favelas que compreende: Morro da Baiana, Morro do Alemão, Alvorada, Nova Brasília, Pedra do Sapo, Palmeiras, Fazendinha, Grota, Matinha, Morro dos Mineiros, Reservatório de Ramos, Casinhas, Morro do Adeus, Areal, Relicário e Coqueiro, considerado oficialmente bairro pela Prefeitura do Rio. Está situado na zona norte do Rio de Janeiro, e, segundo o censo de 2010 do Instituto Brasileiro de Geografia e Estatística (IBGE), existiam 69.143 habitantes contabilizados naquele ano. Porém, os números da Associação de Moradores são discordantes dos dados oficiais por considerarem que o complexo abriga mais de 400 mil habitantes.

O Complexo do Alemão é uma área geográfica marcada pela violência urbana, conforme tem sido veiculado nos meios de comunicação. Começou a receber incentivos públicos depois da ocupação da polícia em 2010, com a instalação de algumas Unidades de Polícia Pacificadora (UPPs), o que "permitiu" a entrada de serviços públicos como o Programa de Aceleração de Crescimento (PAC). Este Programa trouxe obras de saneamento, iluminação, alargamento de ruas e o teleférico que liga cinco estações, ou seja, cinco pontos diferentes do Complexo. Entretanto, essas obras geraram muitos questionamentos e reclamações dos moradores.

A visibilidade do Complexo do Alemão na mídia iniciou-se com a morte do jornalista, da Rede Globo, Tim Lopes, por traficantes, e vem sendo espaço de atuação de muitas ONGs e igrejas. No ano de 2012, virou cenário da novela das $21 \mathrm{~h}$ na TV Globo, "Salve Jorge". Todos esses acontecimentos despertaram a curiosidade sobre o Complexo do 
Alemão e que passou a ser muito sediada até para visitas ilustres, como, por exemplo, o Príncipe Charles. Enfim, é nessa localidade que os integrantes do coletivo \#OcupaAlemão residem e/ou atuam. A seguir, resumimos o perfil dos seus integrantes.

Quadro 1- Perfil dos Integrantes do coletivo \#OcupaAlemão

\begin{tabular}{|c|c|c|c|c|c|c|c|}
\hline & Integrante 1 & Integrante 2 & Integrante 3 & Integrante 4 & Integrante 5 & Integrante 6 & Integrante 7 \\
\hline Escolaridade & $\begin{array}{l}\text { Pós- } \\
\text { graduação } \\
\text { incompleta }\end{array}$ & $\begin{array}{l}\text { Ensino } \\
\text { Médio } \\
\text { completo }\end{array}$ & $\begin{array}{l}\text { Graduação } \\
\text { incompleta }\end{array}$ & $\begin{array}{l}\text { Graduação } \\
\text { completa }\end{array}$ & $\begin{array}{l}\text { Graduação } \\
\text { completa }\end{array}$ & \begin{tabular}{|l|} 
Ensino \\
Médio \\
completo
\end{tabular} & \begin{tabular}{|l|} 
Ensino \\
Médio \\
completo
\end{tabular} \\
\hline $\begin{array}{l}\text { Renda } \\
\text { familiar }\end{array}$ & 2 a 5 salários & $\begin{array}{l}1 \text { a } 2 \text { salários } \\
\text { ( } 2 \text { pessoas } \\
\text { contribuem) }\end{array}$ & $\begin{array}{l}2 \text { a } 5 \text { salários } \\
\text { (4 pessoas } \\
\text { contribuem) }\end{array}$ & $\begin{array}{l}2 \text { a } 5 \text { salários } \\
\text { ( } 3 \text { pessoas } \\
\text { contribuem) }\end{array}$ & $\begin{array}{l}\text { Acima de } 5 \\
\text { salários } \\
\text { (Não } \\
\text { declarou } \\
\text { quantos } \\
\text { contribuem) }\end{array}$ & $\begin{array}{l}2 \text { a } 5 \text { salários } \\
\text { (4 pessoas } \\
\text { contribuem) }\end{array}$ & $\begin{array}{l}2 \text { a } 5 \text { salários } \\
\text { ( } 3 \text { pessoas } \\
\text { contribuem })\end{array}$ \\
\hline $\begin{array}{l}\text { Trabalho dos } \\
\text { pais na maior } \\
\text { parte da vida }\end{array}$ & $\begin{array}{l}\text { Pai: } \\
\text { comerciante } \\
\text { Mãe: } \\
\text { funcionária } \\
\text { pública }\end{array}$ & $\begin{array}{l}\begin{array}{l}\text { Pai: } \\
\text { Construção } \\
\text { civil }\end{array} \\
\begin{array}{l}\text { Mãe: No lar } \\
\text { (sem } \\
\text { remuneração). }\end{array}\end{array}$ & \begin{tabular}{|l} 
Pai: No \\
comércio, \\
banco, \\
transporte, \\
hotelaria ou \\
outros serviços. \\
Mãe: No \\
comércio, \\
banco, \\
transporte, \\
hotelaria ou \\
outros serviços.
\end{tabular} & $\begin{array}{l}\text { Pai: Na } \\
\text { indústria. } \\
\\
\text { Mãe: } \\
\text { Trabalhador } \\
\text { doméstico em } \\
\text { casa de outras } \\
\text { pessoas }\end{array}$ & $\begin{array}{l}\text { Pai: } \\
\text { Construção } \\
\text { civil }\end{array}$ & $\begin{array}{l}\text { Pai: } \\
\text { Construção } \\
\text { civil } \\
\\
\text { Mãe: No } \\
\text { comércio, } \\
\text { banco, } \\
\text { transporte, } \\
\text { hotelaria ou } \\
\text { outros serviços. }\end{array}$ & $\begin{array}{l}\text { Pai: No } \\
\text { comércio, } \\
\text { banco, } \\
\text { transporte, } \\
\text { hotelaria ou } \\
\text { outros serviços. } \\
\text { Mãe: No lar } \\
\text { (sem } \\
\text { remuneração). }\end{array}$ \\
\hline
\end{tabular}

Fonte: Elaborado pelas autoras a partir dos dados obtidos nos questionários e nas entrevistas.

O Complexo do Alemão não deixou os noticiários policiais dos jornais em virtude da violência que o atinge, mesmo depois da instalação de UPPs. A continuidade dos conflitos favoreceu o cenário para a atuação de novos movimentos organizados de luta, como o coletivo \#OcupaAlemão, que até o momento final da pesquisa, março de 2014, era formado por 7 jovens, cuja idade varia entre 24 a 30 anos sendo 4 homens e 3 mulheres.

Em relação à formação intelectual dos participantes, verificou-se que a escolaridade formal varia entre o ensino médio e ensino superior, mas todos eles passaram por entidades com fins sociais (igrejas e ONGs) e histórias de vida bem singulares, como, por exemplo, passagem por internato, um quase envolvimento com o tráfico de drogas, entre outras vivências, que pudemos ter ciência também por entrevistas individuais. Um dos integrantes passou no ano de 2013 para a pós-graduação. Sobre a renda familiar, existem poucas disparidades, prevalecendo uma média de 2 a 5 salários mínimos.

A Internet é o principal meio de informação atual dos pesquisados. O Facebook é a rede social virtual mais utilizada seguida do Youtube. Os principais motivos da maioria, quando acessa as redes sociais, são para continuar a manter contato com os amigos da rede offline e para desenvolver atividades e trabalhos. Assim, os jovens relataram estabelecer uma correlação de vida online e offline.

Em relação ao perfil dos entrevistados, complementarmente aos dados do quadro, destacamos que:

1 - Dos sete integrantes, quatro tiveram envolvimento direto com ONGs e três com ações sociais em igrejas e grupos comunitários. Todos essas consideradas atividades da educação não formal. Vale ressaltar que, desses quatro que passaram por ONGs, três foram por meio de organizações que atendiam jovens já engajados em movimentos socioculturais.

2 - A maioria atribui à escola o início do pensamento crítico sobre a sociedade;

3 - O entretenimento aparece também como finalidade quando acessam as redes sociais ou sites de notícias;

4 - Um dos integrantes traz um aspecto de vivência da rua muito forte, como um lugar de aprendizado e prática política. Entende que a educação informal é importante no processo de 
aprendizagem e mais valorizada que as educações formais e não formais.

Com essa descrição inicial do perfil dos integrantes do coletivo \#OcupaAlemão, será efetuada, a seguir, a análise das entrevistas individuais, das observações na página do Facebook $^{2}$ e das atividades presenciais, sob o ponto de vista dos próprios indivíduos da pesquisa e dos teóricos utilizados.

\section{O Facebook como campo de aprendizado político}

A página do coletivo \#OcupaAlemão fez um ano em janeiro de 2014. Isso facilitou a nossa observação e acompanhamento de todas as postagens, que variavam de uma a três vezes ao dia, com poucos intervalos entre as publicações, sendo de um a dez dias. Na verdade, houve apenas uma única vez que constou um espaço grande de pausa, esses dez dias, que ocorreram durante as festas e férias de final de ano, em 2013.

Percebeu-se, em relação a estas postagens, que não há muitas discussões e debates em relação ao que vem sendo divulgado pelo coletivo na página. São pouquíssimas vezes que se nota um debate em torno de alguma temática levantada desmilitarização, moradia, direitos humanos, entre outros. Porém, a maioria dos temas é somente iniciada no Facebook, desdobrando-se nas atividades presenciais, como, por exemplo, nos encontros de formação política, nas atividades culturais e nas plenárias abertas que geram diferentes tipos de aprendizagens, tanto no campo virtual, quanto nas atividades presenciais.

A partir das análises na página, da observação nas atividades presenciais e da realização das entrevistas semiestruturadas, foi possível notar a ênfase na aprendizagem prática assumida pelo coletivo, que, segundo Gohn (2010), é o processo da dimensão participativa valorizado pela educação não formal.

Verificamos, no entanto, que além da aprendizagem prática, a autora menciona outros tipos aprendizagens as quais destacamos: a) políticas, envolvendo questões relacionadas à aquisição de direitos e às hierarquias dos poderes estatais, b) as aprendizagens culturais: identidades e diferenças culturais dos grupos assim como as diversidades com as quais eles têm que lidar; c) simbólicas: representações existentes sobre determinados grupos; d) cognitivas: aquisição de conhecimentos e a capacidade de relacioná-los aos problemas que lhes dizem respeito e e) reflexivas: práticas e experiências que geram saberes aos indivíduos. Tudo isso também se apresenta fortemente (GOHN, 2010), tanto nas postagens, quanto nas atividades presenciais. O que diferencia, por exemplo, uma aprendizagem política do coletivo para outras instâncias tradicionais como os partidos e os sindicatos, é a forma de abordar, que segundo conta a Integrante 1, o coletivo não partidariza e não teoriza as questões, o que tornaria $\mathrm{o}$ assunto enfadonho, complexo e distante da realidade. Eles costumam aproximar o tema das discussões ao cotidiano dos indivíduos e mostrar como o assunto influencia diretamente em suas vidas.

Portanto, torna-se claro que as aprendizagens percebidas acima correspondem a atividades com intencionalidades bem definidas pelos integrantes do Ocupa Alemão, sendo este outro elemento característico da educação não formal conforme descrevem Gadotti (2005), Libâneo (2007), Trilla e Ghanem (2008) e Gohn (2010). Pode-se perceber pelas postagens realizadas na página de Facebook uma conexão com as atividades realizadas presencialmente e com os acontecimentos recentes. Portanto, no que se refere à página como campo de aprendizado, foi possível notar alguns elementos utilizados para este fim, como, por exemplo, a adoção de uma linha e lógica de postagem [mesmo que haja liberdade para outras mensagens que surjam espontaneamente, como contam ${ }^{3}$ os Integrantes 1 e 7 :

Primeiro tem a lógica de mostrar os nossos trabalhos, individuais. Também tem postagens sobre o Complexo do Alemão, [...] sobre uma rua ou então sobre alguma instituição, algum evento legal que tá rolando aqui ou até mesmo uma análise. Às vezes, coloca foto com parágrafos, fazendo às vezes uma poesia. Em relação tudo que também for relacionado à outra favela, periferia, violência ou até mesmo cultura e evento a gente divulga. Os temas mais especificos que acontecem no mundo, no Brasil. Porque a nossa página fala né... a gente acredita que a favela pode propor demanda pra cidade. (Informação verbal) ${ }^{4}$.

Algumas coisas assim... campanhas que a gente apoia ou abraça, algumas questões, como na época das manifestações. Essa questão do abuso policial, a gente procurava é... postar coisas assim que a gente julga mais nivel de importância maior em alguns horários específicos, de pico e tal, mas no 


\section{geral, é bem livre. (Informação verbal) ${ }^{5}$.}

Essas respostas obtidas com os integrantes permitem observar que há uma intencionalidade na atividade online, que segue a mesma nas atividades offline, como foi possível observar. Esse dado apresenta correlação aos pensamentos dos autores citados acima, os quais afirmam que toda atividade não formal segue uma prática de intencionalidade. $\mathrm{E}$ são essas práticas educativas, culturais e políticas refletidas concomitantemente nos dois ambientes, que contribuem para a formação de uma nova cultura política, como Gohn (2011) defende ser o papel da educação não formal.

Contudo, observamos ainda nos dados que a formação sociopolítica é de preocupação e importância para o coletivo em relação a outros jovens da favela. Por esta razão, criaram-se os encontros formativos do GatoMídia, nos quais defendem que desta forma ajudam a contribuir para despertar o senso crítico e o desejo a participação, bem como Gohn (2011) indica que para a construção da cultura política, enquanto processo político e cultural, deve-se considerar o contexto histórico e a apreensão de processos educativos dados pelas experiências cotidianas. Desse modo, segundo a autora, compreende-se a realidade vivida e ativa, a vontade de lutar para transformá-la.

Todavia, o coletivo não descarta os desafios encontrados no uso das TICs. Nas entrevistas, revelou-se a preocupação em organizar as postagens em um blog, pois percebem que a estrutura do Facebook disposta "em linha do tempo", dificulta a buscallocalização de temas já abordados. Segundo as respostas obtidas, o Facebook contribui para aprendizados pelo contato constante com a leitura (LÉVY, 1999), pela capacidade de trocas, mas é frágil para discussões mais aprofundadas e teóricas. Em virtude de sua estrutura organizada formadora de uma cultura de consumo da informação breve e sucinta, não permitindo a veiculação de um texto muito extenso, este conteúdo deveria, então, ser direcionado a sítios e blogs. Por esta razão, que o uso de imagens é muito utilizado para chamar a atenção, nesse caso. Convém considerar que suprimir determinadas informações requer uma habilidade e capacidade de síntese e entendimento, que é fortemente uma característica dessa geração contemporânea. Logicamente, isso abre margem para informações mal interpretadas e a desinformação.

Em referência a isso, um bom caminho adotado pelo coletivo e que segue na linha dos apontamentos de Pretto (2008), é uma adoção crítica em relação às informações que estão dispostas na Internet. No resultado das entrevistas, todos os integrantes disseram pesquisar em mais de duas fontes. Entre as mídias alternativas online apareceram: Brasil de Fato, Vírus Planetário, Carta Capital, Observatório da Imprensa; entre as mídias tradicionais online: O Dia, O Globo, O Extra, Folha de São Paulo; e alguns perfis pessoais de relevância política: Junior Perin, Marcus Faustini, entre alguns professores acadêmicos e jornalistas. Porém, também constatamos pelas entrevistas que o contato com a mídia tradicional segue mais em nível de comparação sobre o tratamento da notícia dada pelos meios não tradicionais, e geralmente o ponto de vista dos integrantes é reproduzido na página. Essa capacidade de leitura crítica do mundo demonstrada acima é atribuída pela maioria dos integrantes do \#OcupaAlemão, como tendo sido adquirida nas atividades das ONGs das quais fizeram parte, corroborando as interpretações de Gohn (2010) e Gadotti (2005) ao afirmarem que a educação não formal é um espaço relevante para a formação cidadã. Porém, alguns entrevistados citaram a importância do espaço acadêmico na construção crítica e reflexiva - isso foi apontado por dois dos integrantes que estão na universidade. A Integrante 1 destaca ainda que essa capacidade de leitura crítica da sociedade é exposta hoje no Facebook, e a participação política pode ser estimulada pela Internet, pelo contato com outras vozes e resistências parecidas:

Eu acho que a internet [...] ela estimula, ela pode estimular as pessoas para irem pra rua. Não que ela vai "ai meu Deus" resolver todos os problemas, mas acho que na internet as pessoas falam o que pensam né, e elas podem ser contestadas ao mesmo tempo. Então, talvez estimule as pessoas colocarem pra fora o que elas estão pensando [...] ali elas vão encontrar outras pessoas que pensam a mesma coisa, e talvez pensar que elas podem fazer algo. Acho que o meio de encontrar pessoas que pensam a mesma coisa que você, e até de contestar pessoas que não pensam também, e acho que sim, estimula a participação política. (Informação verbal) $^{6}$.

No caso da página de Facebook do coletivo, os integrantes buscam estimular seus iguais e desiguais, principalmente, por imagens carregadas de significados, a refletir e participar na garantia de 
direitos. É o que podemos notar na sequência de postagens abaixo ${ }^{7}$, nas quais a indignação pelo fato ocorrido não somente gerou debate no espaço da página, como também houve muitos compartilhamentos, somando mais de mil. Foi uma publicação relacionada à outra favela do Rio, o Complexo da Maré.

Figura 1 - A Manifestação na Maré (1 ${ }^{\text {a }}$ sequência de debate)

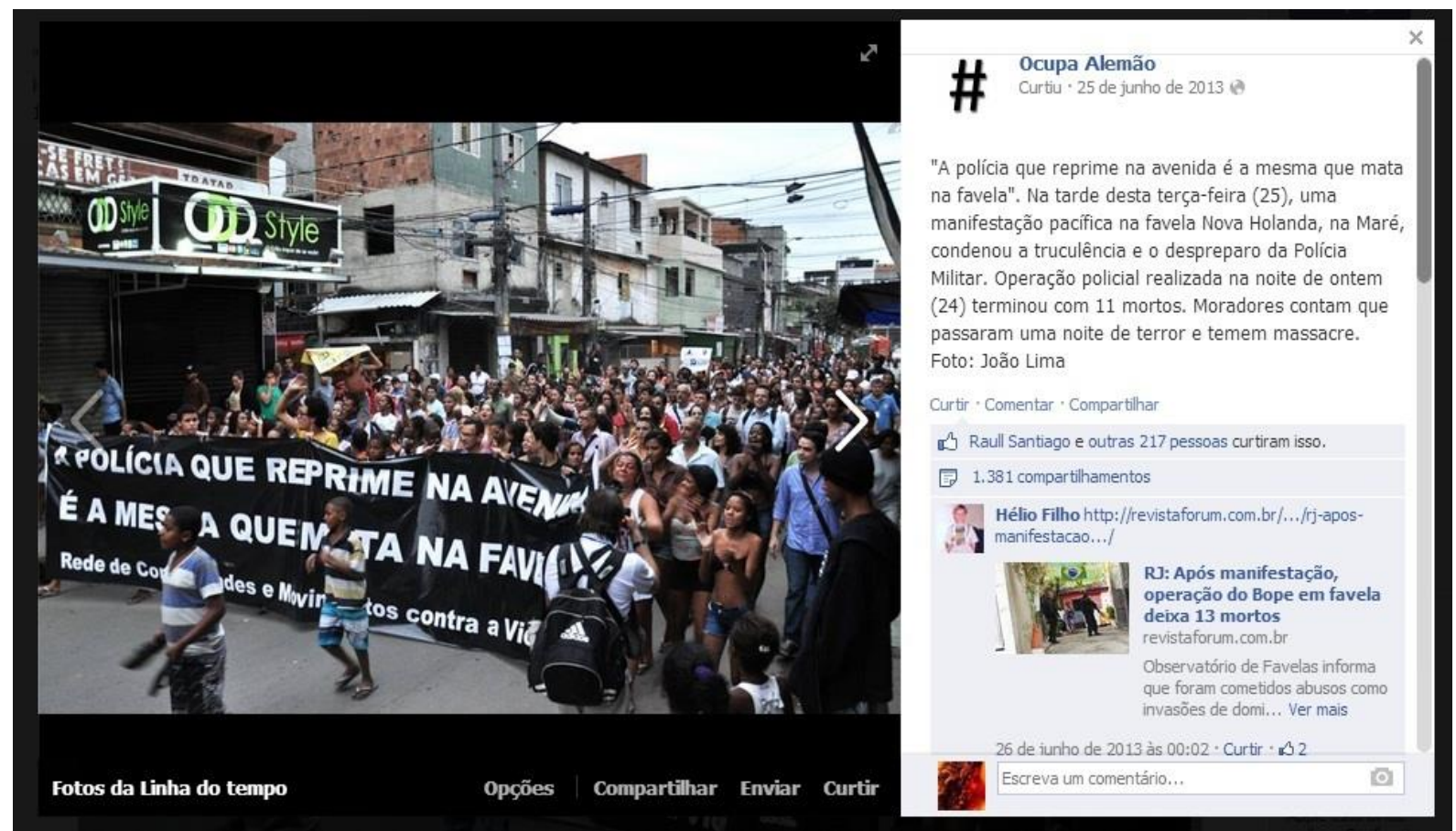

Figura 2 - A Manifestação na Maré (2 ${ }^{\mathbf{a}}$ sequência de debate)

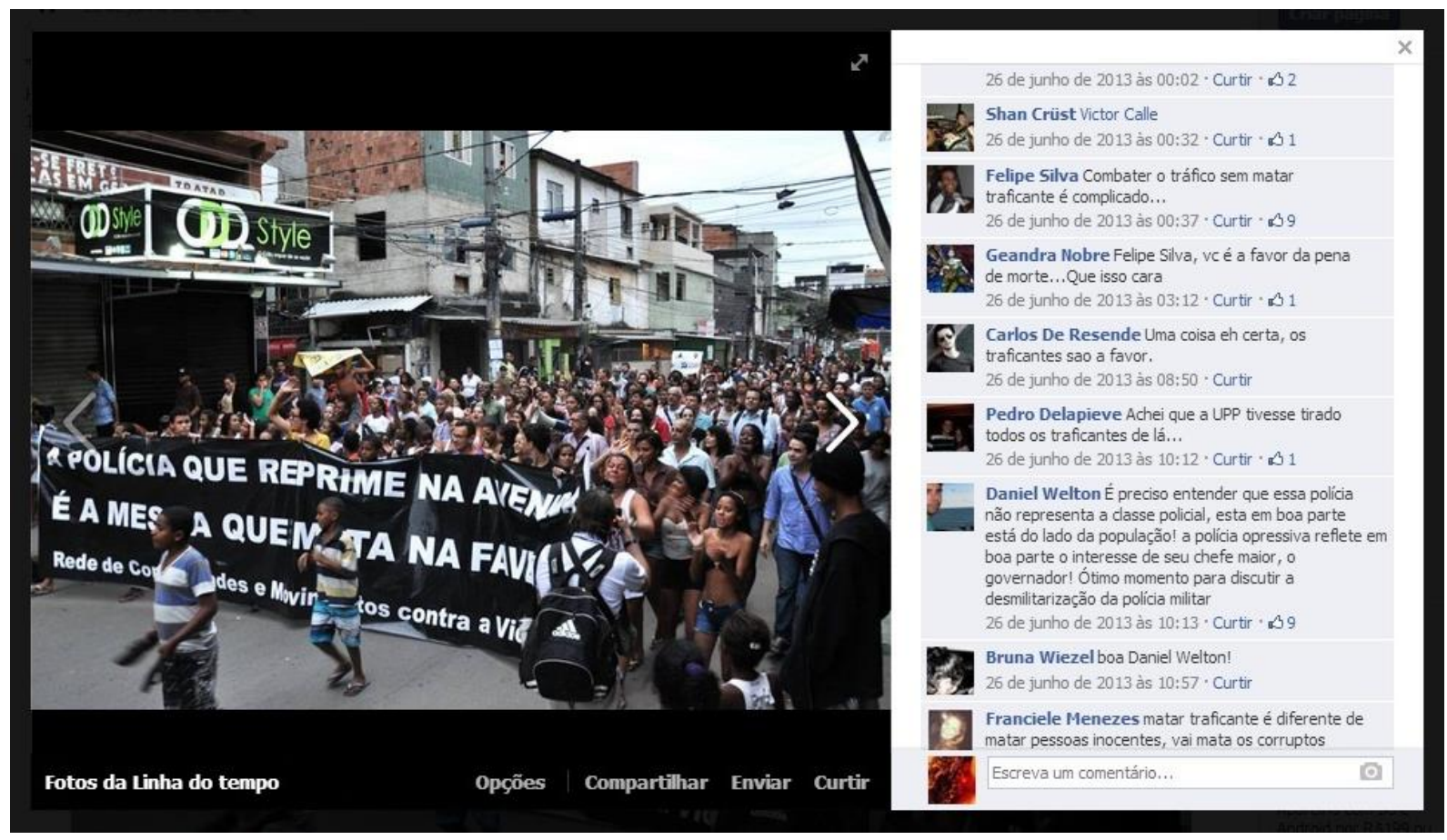

Essa postagem sobre a manifestação na favela da Maré tem mais uma sequência de debate e foi, até janeiro de 2014, a mais comentada na página do \#OcupaAlemão, mas não maior que a quantidade 
de compartilhamentos e curtidas sobre o ato que reuniu entre moradores, ativistas de direitos humanos, ONGs, movimentos diversos, artistas e intelectuais da sociedade que foram contrários à atitude da polícia na favela. E, conforme anteriormente mencionado, houve sensibilização com a causa pela Internet, sendo possível estimular e convocar para a participação política tanto no espaço presencial quanto no espaço virtual.

Conforme abordamos, são poucas as vezes que percebemos debates na página, no entanto, Pierre Lévy (1999), Castro (2012) e Pretto (2008) identificam que a construção de aprendizados e conhecimentos não se dá somente por meio de diálogos textuais, mas a partir dos diversos contatos, os quais apontamos por meio de visualizações, quando o indivíduo tem contato com a leitura [visual e audiovisual - fotos, vídeos, leituras de textos, etc.], que o ajuda a construir um pensamento a favor ou contrário ao que foi dito, o que também acontece quando curtimos ou compartilhamos alguma das postagens divulgadas, pois é uma forma de posicionamento sobre o assunto. São esses contatos pela cultura digital que tem favorecido a nova leitura de mundo (LÉVY, 1999) e a contribuição para o novo “cidadão comunicador" (CASTRO, 2012).

É possível observar que este novo cidadão vem sendo estimulado pelas ONGs que utilizam em suas atividades as mídias (GOHN, 2013), com o propósito, muitas das vezes, de capacitar seus atendidos para que se apropriem das TICs e lutem por seus direitos. Este é um caminho adotado pelo coletivo \#OcupaAlemão em uma de suas atividades, conforme afirma a Integrante 2: "A gente tá fazendo o GatoMídia pras pessoas se apropriarem das tecnologias pra lutar pelos seus direitos". A Integrante 1 complementa que a ideia é mostrar soluções simples, por exemplo, como fazer denúncias em rede, como montar uma página de Facebook ou fazer um evento de convocação na rede social. Parece ser simples, mas existem horários específicos de postagens, uma forma de estrutura textual e de composição de imagens, estratégias para aumentar as curtidas, e assim por diante.

Sobre isto, é notável o poder de força de uma página. No caso do \#OcupaAlemão, verificamos que há muitos compartilhamentos, visualizações e curtidas. Isso ocorre pela identificação com o que é postado. Na ilustração abaixo, podemos notar a nossa afirmação. Foi feito um discurso político de assumir como positivo o termo "farofeiro", representação simbólica que gera aprendizados (GOHN, 2010), designado ao comportamento dos frequentadores suburbanos nas praias da zona sul do Rio.

Figura 3 - Ato "Farofaço"

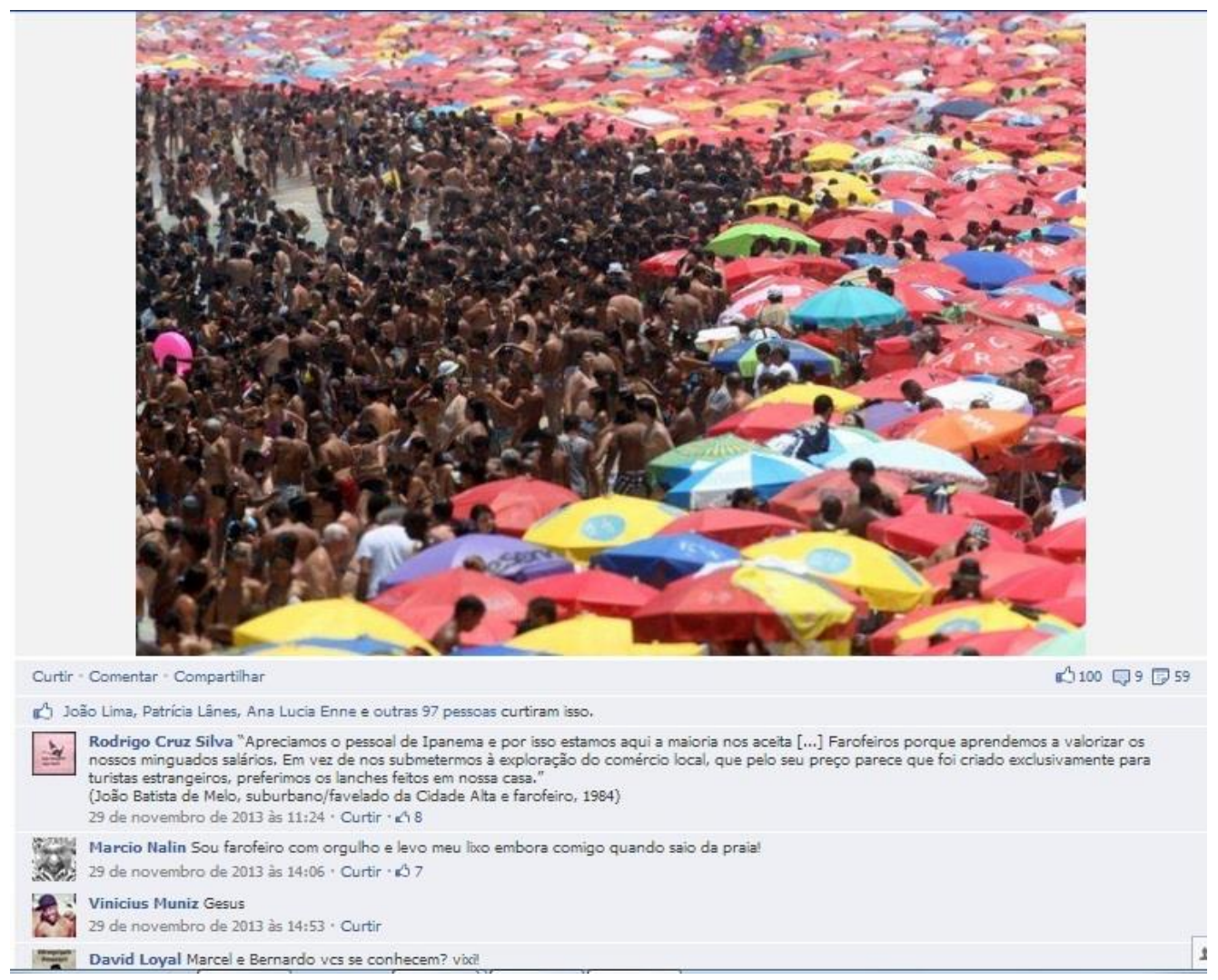

Horizontes, v. 34, n. 1, p. 159-172, jan./jul. 2016 


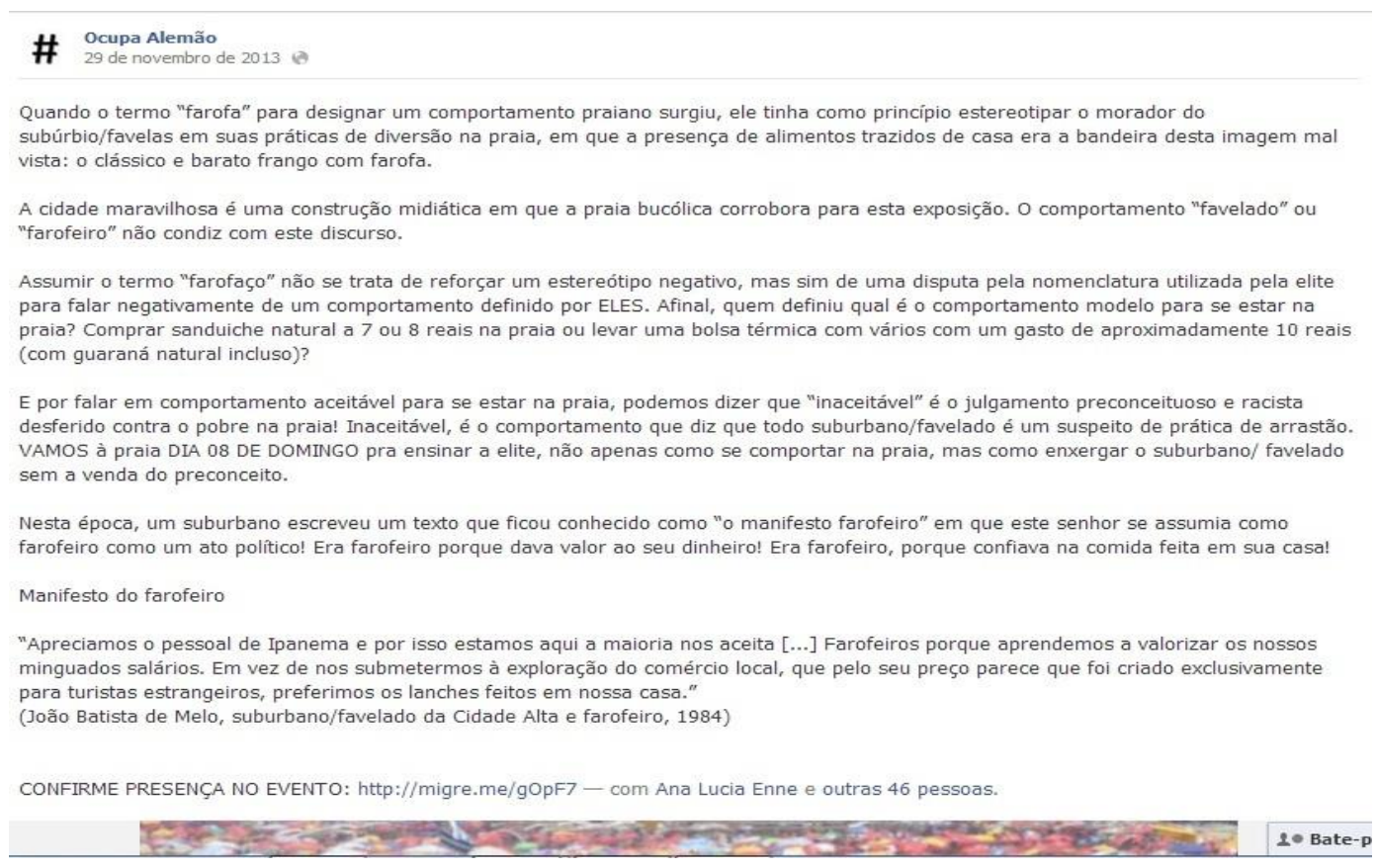

Essa ação, chamada de "Farofaço", aconteceu em novembro de 2013, puxada pelo coletivo \#OcupaAlemão no espaço público do calçadão da praia de Ipanema, depois de acontecer alguns arrastões em praias da zona sul do Rio e a mídia abordar o assunto por um lado preconceituoso e racista, como se todo pobre na praia fosse suspeito de participar de arrastões. Essa indignação fomentou as discussões na rede social e se transformou em atividade concreta. $\mathrm{O}$ evento também foi uma crítica aos serviços públicos mal prestados que impedem o direito de ir e vir dos cidadãos na cidade, como os transportes. Este, ato com repercussão midiática ${ }^{8}$, teve mobilização e organização no Facebook, como podemos verificar pela criação de um evento na rede virtual, Ilustração 2 A, com concomitância da ação prática no espaço público como já comentado.

Como mencionamos anteriormente, o uso das TICs pelo coletivo coaduna-se com uma dimensão política, de luta por direitos, a qual é uma potencialidade da educação não formal (GOHN, 2010). E para disputar politicamente dentro do campo de poder da Internet, alguns códigos necessitam ser acionados, como saber melhores dias e horários para postagens; como conseguir grandes visualizações; como tornar um assunto viral; que tipo de texto e imagem funcionam mais, etc. Referente a isso, notamos que algumas visualizações, quantidade de vezes que viram a postagem, são provocadas intencionalmente pelo coletivo, como podemos analisar na ilustração $2 \mathrm{~A}$, que ocorre a partir de marcações de pessoas que os integrantes julgam ser importantes. Desta maneira, a postagem aparece no perfil da pessoa marcada e mais pessoas podem visualizar e compartilhar - esta é uma estratégia de disseminação da informação. Nota-se também na imagem seguinte, ilustração $2 \mathrm{~B}$, que há mais curtidas e compartilhamentos do ato, do que de um debate em torno da ação. Este movimento, porém, de curtir e compartilhar são entendidos pelos integrantes do coletivo como formas de posicionamento sobre o assunto divulgado, logo uma leitura de mundo.

Neste caso, a página seria um espaço de aprendizado político, conforme apontam quatro dos integrantes. Porém, um ressalta que este tipo de aprendizado também dependerá da vontade do indivíduo de querer participar, pois se este não quiser, não será a página a responsável, como apontam Castells (1999) e Lévy (1999). Acrescentamos a esta ressalva levantada, que é preciso estimular a educação para a cidadania (GOHN, 2010, 2011, 2013), uma vez que ela ativa o conhecimento, o senso crítico e a participação, e também auxilia a criar espaços democráticos para decisões (GADOTTI, 2005), como as ações de educação não formal, em boa parte, têm realizado.

No que tange à contribuição do Coletivo para o aprendizado político na página do \#OcupaAlemão, três integrantes hesitaram em destacar essa contribuição, mas curiosamente, quando perguntados 
sobre quais os meios de comunicação que mais utilizam para obter informação política, todos respondem que procuram na Internet, principalmente nas redes sociais virtuais. As outras mídias de informação mencionadas foram: jornal impresso e TV.

Raro eu ver jornal. Às vezes quando tô vendo que tá todo mundo postando, por exemplo, vou dá exemplo de novo de manifestação que é uma coisa que tá acontecendo muito. As pessoas estão postando que tá tendo repressão, às vezes, eu ligo a Globo pra ver o que tá passando lá pra meio que comparar. Mas tirando isso eu vou muito assim, no nicho, sei lá... eu quero saber sobre o que tá acontecendo na educação eu vou em fanpage, hoje em dia é assim. Vou em fanpage até de jornal mesmo, sei lá, O Globo, O Dia, vou em fanpage de movimento social que tá cobrindo... Vírus Planetário, jornal Brasil de Fato, [jornal] $O$ Cidadão... eu vou nas fanpages, eu procura muito mais na Internet, notícia, ou então a notícia vem até a mim né?! Tá lá, olhando tudo, e alguém compartilha alguma parada. (Informação verbal) ${ }^{9}$.

Os integrantes do coletivo reconhecem o aprendizado político em páginas do Facebook e em outros espaços da Internet, porém não é unanimidade entre eles que sua página também possa servir para informação e formação política das pessoas que os acompanham, com receio de se mostrar presunçosos. Porém, apontamos que há aprendizado político, a partir das trocas de conhecimentos nas postagens, para isso, recorremos a Lévy (1999) ao advertir que esse aprendizado é gerado pelos contatos com discursos, vozes e significados ao contribuir para uma leitura crítica do mundo, ajudando a surgir o que o próprio autor chama de inteligência coletiva. E observamos que o mesmo acontece nos encontros de formação política do GatoMídia, onde presencialmente com outros jovens, o coletivo promove discussões dos assuntos que são levantados na Internet.

No que tange à indagação sobre a página \#OcupaAlemão ser formadora de opinião e influenciar pensamentos nas pessoas, a maioria, totalizando cinco integrantes, respondeu que acredita que ela tem este papel sim porque eles compartilham seus ideais de vivência prática. Por isso, imprimem credibilidade à página. Apenas dois entrevistados se mostram receosos com a palavra "formador" porque acreditam ter um peso forte, e acham que a página apenas é informativa, ou seja, agrega e acrescenta algo à opinião existente de cada indivíduo, que até podem divergir nos pensamentos, como aponta o Integrante 5: "Eu acho que formador não diria. Acho que eu diria informativo, de trazer pra mais próximo das discussões. Eu acho que nossa ideia não é formar não. Acho que a ideia é fazer com que as pessoas participem. A formação vai vir de outros lugares, do contexto social daquela pessoa".

Este integrante enfatiza que a página sozinha não é o único elemento provocador de aprendizados. Pode partir do indivíduo ou não o aprendizado, mas certamente outros espaços contribuem para a sua formação política como os outros integrantes relatam ao serem perguntados sobre quais espaços identificavam como sendo importantes ao desenvolvimento do aprendizado político hoje na sociedade. Três identificaram os espaços das ONGs, dois mencionaram a rua como espaço privilegiado, um a Internet e outro integrante diz não se lembrar de nenhum espaço de aprendizado político.

Os espaços aqui apontados pertencem a dois tipos de educação, a não formal e a informal. Porém, enfatizamos na pesquisa, a educação não formal por ela ser o espaço e o contato com o pensamento crítico e sociopolítico, como assim afirmam Gadotti (2005) e Gohn (2010). No entanto, Trilla (2008) aponta, e não desconsideramos, que a educação não formal é atravessada pela educação informal ${ }^{10}$. A educação não formal traz outras funções educativas, e ainda estabelece interações funcionais e intromissões mútuas com as educações formais e informais. E Libâneo (2007), por sua vez, defende que mais do que atravessamento de uma com a outra educação, há uma interpenetração entre todas as formas de educação. Logo, podemos concluir que há influências de diversos espaços de aprendizagem na construção dos conhecimentos, mas o espaço formativo mais citado, em vários momentos das entrevistas, foram as ONGs.

Como são definidos pelos autores: Gadotti (2005), Libâneo (2007), Trilla e Ghanem (2008) e Gohn (2010), a educação não formal é caracterizada por sua intencionalidade, o que fica claro nas entrevistas porque todos sabem os temas $\backslash$ pautas que entram na página. Essa intencionalidade das ações educativas nos espaços não formais de ensino, segundo Gohn (2010), é um processo para a formação da cidadania. Logo, mesmo que alguns integrantes tenham receio em admitir que a página a qual gerenciam no Facebook contribui diretamente 
para formação de aprendizados, sobretudo político, é o conjunto de atividades que realiza tanto online, pelas divulgações e compartilhamentos, quanto offline, pelas atividades de intervenção, encontros de discussão políticas, etc., que favorecem a troca de conhecimentos muito além da Internet (PRETTO, 2008). Os próprios integrantes afirmam, quando indagados na entrevista, por essa perspectiva apresentada pelo autor, se o Facebook mobiliza, influencia pensamentos e decisões políticas:

Sim, com certeza. O caso do Thiago, o rapaz, o que tomou um tiro, a gente começou a mobilizar um pessoal pra fazer um tuitaço, e chamou atenção pra aquele caso ali. [...] vieram até mim, na rede, pra perguntar o que era aquilo, o que tava acontecendo, se poderia ajudar de alguma forma, e pra entender o que tinha acontecido, e trazendo discussões mesmo, com relação à segurança pública. Eu acho que esse caso me dão essa certeza. (Informação verbal) ${ }^{l 1}$.

Eu acredito que sim. A gente posta ali coisas do dia-a-dia, que muitas vezes, é fora do imaginário de quem não vive na favela. Então, a gente provoca um olhar diferente sobre aquela realidade. (Informação verbal $^{12}$.

Eu acho que sim. Eu até vejo nos meninos que tão participando lá da oficina do GatoMidia, eles compartilham e curtem as nossas publicações. Eles acabam passando isso tudo também pra suas redes. (Informação verbal) $)^{13}$.

Influencia. No Face é muito mais fácil você marcar ali, antes de marcar presencial, você fazer um debate, abrir um grupo de discussão, abrir um chat de discussão. É muito mais prático. É uma ferramenta de mobilização. Mas se a pessoa não quiser se mobilizar, não é o Facebook que vai fazer a pessoa se mobilizar. O Facebook é uma ferramenta pra quem quer se mobilizar. (Informação verbal) $)^{14}$.

Como na Internet a aprendizagem se dá de maneira horizontal, não tendo a forma hierárquica do "detentor do saber" (COUTO JUNIOR, 2012), os saberes e conhecimentos podem ser absorvidos ou esvaídos. Logo, a defesa desse estudo é para que tenhamos uma formação educativa de troca entre adultos e jovens, de como utilizar a técnica e a potência de criação e aprendizados na Internet e outras TICs. Pois, se não houver um estímulo, corremos o risco de termos mais uma mídia para uso em massa para a passividade e superficialidade.

A escola, por sua vez, é vista como um espaço importante para a construção de uma postura crítica na sociedade por dois integrantes, 6 e 7; ou ainda tem o papel de base para o conhecimento inicial da vida ou valorizam o desenvolvimento de determinadas habilidades, tais como: saber ler, escrever e fazer contas, conforme relatam os integrantes 1, 2, 3, 4 e 5. Mas estes 5 integrantes criticam o modelo de educação por estar moldada em métodos antigos, que não avançaram com as mudanças na sociedade, conforme Andrade e Neto (2007) afirmam que a escola expressa, ao longo dos tempos, enormes desigualdades entre os jovens brasileiros. Porém, da mesma forma que desaprovam os rumos da educação formal, também repreendem muitas formas de atuação principalmente das ONGs e Organizações do Terceiro Setor, que repetem e reproduzem os modelos fechados da escola, costumam não se articular nas favelas, não são transparentes com os recursos públicos que recebem e não mostram resultados para a sociedade, o que vai ao encontro das reflexões de Sposito (2008) sobre os problemas da educação não formal.

O Integrante 6 afirma que muitas organizações sociais, que não conhecem o Complexo do Alemão, se apropriam do conhecimento comunitário e se aproveitam dos vínculos governamentais e empresariais que têm, para elaborar pesquisas e relatórios de uma falsa realidade e, assim, conseguir aprovação em projetos com financiamento envolvendo grandes valores, mas não deixam legados no território, como, por exemplo, algum equipamento para continuidade dos atendidos pelas ações.

Todos os integrantes, de certa maneira, analisam criticamente a postura das ONGs nos territórios das favelas, como também o fazem com as instâncias estatais, e procuram apresentar propostas de mudanças a partir das práticas sociais na rede e em redes [online e offline]. Portanto, consideram importantes esses espaços para troca de aprendizados e conhecimentos coletivos, pois a Internet hoje aguçou e amplificou os modos e as formas de aprender e conhecer (LÉVY, 1999) e de ser um novo cidadão comunicador (CASTRO, 2011). É este meio que nos permite o acesso a diferentes culturas, opiniões e informações, aproximando novos e 
antigos atores sociais, por causas comuns, por meio de sua convergência midiática e por diferentes redes sociais existentes na sociedade (CASTRO, 2011).

\section{Considerações finais}

A diferença de comportamento em relação ao uso das TICs é verificada pelo fato que as gerações mais recentes estão cada vez mais próximas delas como modo arquétipo de interação, criação e rapidez, o que facilita a dinamização das ações entre os jovens moradores de periferias. A caracterização da sociedade em rede efetuada por Castells (1999) parece não ter proximidade com instituições educativas e essas não se tornaram atrativas aos jovens participantes da pesquisa que apontam as suas deficiências e também não poupam de críticas às ONGs.

Os integrantes do \#Ocupaalemão percebem que a construção de seus aprendizados ocorrem em espaços distintos, em consonância com as reflexões de Gohn (2010) e Gadotti (2005), ao vislumbrarem os espaços não formais como potencializadores de uma criticidade pelos cidadãos, conforme foi apontado nas entrevistas individuais ao reconhecerem as diferentes vivências como importantes à formação política do grupo. Eles citaram, como exemplo, dois membros que só possuem o ensino médio e tiveram histórias de vida marcadas pela exclusão social. Esses jovens foram apontados pelos outros cinco colegas como referências para o grupo pela capacidade de elaborar textos políticos viscerais e precisos. É o que Gohn (2013) em uma entrevista mencionou sobre a capacidade de aprendizagem dos ativistas que refletem e sintetizam a partir das práticas cotidianas.

De uma maneira geral, percebemos que os integrantes do \#OcupaAlemão, pelo perfil socioeconômico e étnico-cultural, pelas entrevistas e observação presencial, se aproximam das ideias de Gramsci (1978), quando o autor descreve o intelectual orgânico, pois reúnem conhecimentos diferentes que se complementam para transformar a sua realidade, apesar dos níveis diferenciados de educação escolar e práticas de vida. Nesse quesito, é perceptível que as vivências que fortaleceram os integrantes dentro do coletivo decorrem da experiência que muitos desses jovens tiveram em organizações sociais, seja nas ONGs, igrejas e organizações comunitárias.

É possível afirmar, a partir dos resultados dessa pesquisa, que a Internet e as redes sociais virtuais são hoje os novos canais de transformação suscitados pelos modos de produção, circulação e consumo cultural, e, por isso, é impossível separar a potência de interação das ações online e offline, conforme foi mencionado, muitas vezes, elas se retroalimentam.

A potência da cultura digital está na possibilidade de ser construída tanto individualmente como coletivamente, e podemos verificar isso nas revoluções que vem sendo transmitidas midiaticamente pelos dispositivos móveis, celulares e tablets, que se transformaram em novas "armas" de democracia dos mais jovens. Em suma, as TICs, principalmente as apresentadas nesta pesquisa como as mais utilizadas pelos jovens do \#OcupaAlemão: Facebook, Internet e o celular conectado à rede online, são hoje suas novas "armas" comunicadoras e de proteção para uma nova democracia.

\section{Notas}

1 Disponível em: < <http:/op.ceptro.br/cgibin/cetic/tic-domicilios-e-empresas-2011.pdf $>$.

Acesso em: 11 jan. 2014.

$2 \mathrm{O}$ acompanhamento das postagens na página do Facebook do \#Ocupalemão ocorreu no período de agosto de 2013 a abril de 2014.

3 Foram respeitadas as falas dos integrantes na sua oralidade.

4 Explicação da Integrante 1.

5 Explicação da Integrante 7.

6 Explicação da Integrante 1.

7 Esclarecemos que as postagens do coletivo \#Ocupaalemão são de domínio público, https://www.facebook.com/OcupaAlemao?fref=ts

8 Repercussão na mídia sobre o ato "Farofaço" puxado pelo coletivo \#OcupaAlemão: Disponível em: $\quad<\mathrm{http}: / /$ rjalerta.com/post/manifestantespromovem-farofaco-na-praia-de-ipanema $>\quad$ e http://www.portalsoma.com.br/noticias/rj/manifest antes-promovem-farofaco-na-praia-deipanema.html

9 Explicação da Integrante 1.

10 A educação informal acontece nas experiências diárias e na relação com os meios: família, religião, meios de comunicação, a rua, etc., onde adquirimos habilidades e conhecimentos (TRILLA, 2008).

11 Explicação da Integrante 4.

12 Explicação da Integrante 7.

13 Explicação da Integrante 5.

14 Explicação da Integrante 1. 


\section{Referências}

ANDRADE, E. R.; NETO, M. F.. Juventudes e trajetórias escolares: conquistando o direito à educação. In: ABRAMOVAY, M.; ANDRADE, E. R.; ESTEVES, L. C. G. Juventudes: outros olhares sobre a diversidade. Brasília: Ministério da Educação, Secretaria de Educação Continuada, Alfabetização e Diversidade; Unesco, 2007.

CASTELLS, M. A sociedade em rede. Tradução: Roneide Venâncio Majer; atual. 6. ed.: Jussara Simões São Paulo: Paz e Terra, 1999. (A era da informação: economia, sociedade e cultura; v. 1).

CASTRO, M. R. de.; FERREIRA, G..; GONZALEZ, W.. Metodologia da pesquisa em educação. Nova Iguaçu, RJ: Marsupial Editora, 2013.

CASTRO, O. A cultura digital e o direito à comunicação. TICs Domicílios e Empresas 2011. Pesquisa sobre o Uso das Tecnologias de Informação e Comunicação no Brasil - São Paulo: Comitê Gestor da Internet no Brasil, 2012. Disponível em: $<$ http://op.ceptro.br/cgi-bin/cetic/tic-domicilios-eempresas-2011.pdf $>$. Acesso em agosto de 2015.

IBASE. Comunicação e juventudes em movimento: novas tecnologias, territórios e desigualdades. Pesquisa Jovens pobres e o uso das NTICs na criação de novas esferas públicas democráticas. Rio de Janeiro: Ibase, 2013. Disponível em: $<$ http://issuu.com/ibase/docs/ibasejuventude_issuu $>$ . Acesso em agosto de 2015.

COUTO JUNIOR, D. R. Cibercultura, juventude e alteridade: aprendendo-ensinando com o outro no Facebook. Dissertação (Mestrado em Educação) Universidade do Estado do Rio de Janeiro, Rio de Janeiro, 2012.

FRAGOSO, S.; RECUERO, R.; AMARAL, A. Métodos de pesquisa para internet. Porto Alegre: Sulina, 2011. (Coleção Cibercultura).

GADOTTI, M. A questão da educação formal/não formal. Disponível em: $<$ http://www.virtual.ufc.br/solar/aula_link/llpt/A_a
H/estrutura_politica_gestao organizacional/aula 01 /imagens/01/Educacao_Formal_Nao_Formal_2005. pdf $>$. Acesso em agosto de $201 \overline{5}$.

GOHN, M. da G. Educação não formal e o educador social: atuação no desenvolvimento de projetos sociais. São Paulo: Cortez, 2010. (Coleções questões da nossa época; v. 1).

Educação não-formal e cultura política: impactos sobre o associativismo do terceiro setor. 4. ed. São Paulo: Cortez, 2011. (Coleção questões da nossa época; v. 26).

. Movimentos sociais no início do século XXI: antigos e novos atores sociais. Maria da Glória Gohn (Org.). 6. ed. Petrópolis, RJ: Vozes, 2013.

GRAMSCI, A. Os intelectuais e a organização da cultura. Tradução Carlos Nelson Coutinho. 2. ed. Rio de Janeiro: Civilização Brasileira, 1978.

LÉVY, P. Tradução de Carlos Irineu da Costa. Cibercultura. São Paulo: Ed.34, 1999.

LIBÂNEO, J. C. Os significados da educação, modalidades de prática educativa e a organização do sistema educacional. Pedagogia e pedagogos, para quê? São Paulo: Cortez, 2007. p. 69-103.

PRETTO, N. De L. Uma escola sem/comfuturo. Campinas, SP: Papirus, 1996 - (Coleção Magistério: Formação e Trabalho Pedagógico).

Escritos sobre educação, comunicação e cultura. Campinas, SP: Papirus, 2008.

SPOSITO, M. P. Juventude e Educação: interações entre a educação escolar e a educação não formal. Revista Educação e Realidade, jul/dez 2008, p. 8398.

TRILLA, J.; GHANEM, E. Educação formal e não formal: pontos e contrapontos. Jaume Trilla, Elie Ghanem; Valéria Amorim Arantes (Org.). São Paulo: Summus, 2008. 
Sobre as autoras

Ana Paula Silva: Mestre em Educação UERJ/ FEBF. Pesquisadora pela Faculdade Latinoamericana de Ciências Sociais (FLACSO-BRASIL) e consultora de comunicação da Secretaria Nacional de Juventude pela UNESCO.

Wania Gonzales: Doutora em Educação UFRJ. Professora adjunta, colaboradora, do Mestrado em Educação da UERJ/ FEBF e professora adjunta, do corpo permanente, do Programa de Pós graduação da Estácio.

Recebido em setembro de 2015.

Aprovado em fevereiro de 2016. 